Article

\title{
Carbon-Coated Nickel Nanoparticles: Effect on the Magnetic and Electric Properties of Composite Materials
}

\author{
Artyom Plyushch ${ }^{1, *}$, Jan Macutkevič ${ }^{1}$, Jūras Banys ${ }^{1}$, Polina Kuzhir ${ }^{2,3}$ (D), Nikolay Kalanda ${ }^{4}$, \\ Alexander Petrov ${ }^{4}$ (D) , Clara Silvestre ${ }^{5}$ (D), Mikhail A. Uimin ${ }^{6,7}$ (D), Anatoly Ye. Yermakov ${ }^{6,7}$ (iD) \\ and Olga Shenderova ${ }^{8}$ \\ 1 Faculty of Physics, Vilnius University, Sauletekio 9, Vilnius LT-10222, Lithuania; \\ jan.macutkevic@gmail.com (J.M.); juras.banys@ff.vu.lt (J.B.) \\ 2 Research Institute for Nuclear Problems of Belarusian State University, Bobruiskaya Str., 11, \\ Minsk 220030, Belarus; polina.kuzhir@gmail.com \\ 3 Tomsk Polytechnic University, Lenin Ave, 30, Tomsk 634050, Russia \\ 4 Scientific-Practical Materials Research Centre of the National Academy of Sciences of Belarus, \\ P. Brovka Str. 19, Minsk 220072, Belarus; kalanda362@gmail.com (N.K.); altair2006@gmail.com (A.P.) \\ 5 Consiglio Istituto per i Polimeri, Compositi e Biomaterialii, Via Campi Flegrei 34, 80078 Pozzuoli, Italy; \\ clara.silvestre@ipcb.cnr.it \\ 6 M.N. Mikheev Institute of Metal Physics, Ural Branch of the Russian Academy of Sciences, \\ Yekaterinburg 620137, Russia; uimin@imp.uran.ru (M.A.U.); yermakov@imp.uran.ru (A.Y.Y.) \\ 7 Institute of Natural Sciences, Ural Federal University, Yekaterinburg 620083, Russia \\ 8 Adamas Nanotechnology Inc, 8100 Brownleigh Dr, Raleigh, NC 27617, USA; oshenderova@adamasnano.com \\ * Correspondence: artyom.plyushch@ff.vu.lt
}

Received: 23 March 2018; Accepted: 25 April 2018; Published: 27 April 2018

check for updates

\begin{abstract}
Nickel nanoparticles coated with few layers of carbon have been embedded into the polydimethylsiloxane (PDMS) matrix in concentrations up to $11 \mathrm{vol} \%$. Dielectric and magnetic properties of composite materials have been studied in wide frequency $(20 \mathrm{~Hz}-1 \mathrm{MHz})$ and temperature $(130-430 \mathrm{~K})$ ranges. It was demonstrated that the temperature behavior of dielectric properties is determined by glass transitions in the PDSM matrix below $200 \mathrm{~K}$ and the Maxwell-Wagner relaxation above room temperature. The possibility of using fabricated composites on the basis of the PDMS matrix for producing a wide range of passive electromagnetic components, such as frequency-selective filters, wide-band detectors/sensors of a bolometric type, and even electromagnetic "black holes" is also discussed.
\end{abstract}

Keywords: composite materials; dielectric properties; magnetic properties; glass transition; superparamagnetic particles

\section{Introduction}

Recently composites based on polymer matrices with the inclusion of magnetic nano-sized particles has become a point of interest of many research groups. Interest is mainly focused on elastomagnetic effects [1] and the wide prospects of applications as actuators, sensors [2-5], and shape-memory materials [6,7]. These materials also demonstrate prospects for biomedicine [8,9], recording media, and high-frequency applications [10-12].

Being ferromagnetic or superparamagnetic Ni nanosized particles are very promising materials for electromagnetic absorbing devices. The attenuation of such type of composites may reach up to $50 \mathrm{~dB}$ [13]. It was recently demonstrated that absorption properties depend on nanoparticle 
fractions [12], the average size of nanoparticles [11], and the influence of graphite shell on a particle's surface [14]. However, the thermal behavior of broadband dielectric and magnetic properties has not been studied yet.

Polydimethylsiloxane (PDMS) is a well known polymer for bioapplications [15] and 3D-printing [16]. The glass transition in PDMS occurs below room temperature [17], so in normal conditions it is the soft material. One of the main applications of PDMS is the production of stamps and molds for soft lithography [18-20]. For the purposes of soft lithography, the controllable glass transition $\left(T_{g}\right)$ temperature is important because of the difference in properties below and above $T_{g}$ [21]. It is also important to produce composite materials based on PDMS matrices with variable properties of PDMS, such as stiffness and hydrophobicity [22], conductivity [23,24], and thermal, mechanical [25], and magnetic properties [26]. Due to the appearance of magnetic properties Ni@C/PDMS composites might be used for effective absorption of electromagnetic waves in a wide spectral range, achieving better impedance matching when organizing them into regular structures by, e.g., 3D printing. Combining two strategies, (i) the addition of Ni@C to PDMS and (ii) the 3D printing of different mashes with particular geometries using magnetic PDMS, it will be possible to develop a wide range of passive electromagnetic components, such as frequency-selective filters, wide-band detectors/sensors of a bolometric type, and even electromagnetic perfect absorbers [27-29] (so-called "black holes" or wave concentrators).

In this paper, we study the dielectric and magnetic properties of composite materials based on a PDMS matrix with different concentrations of nanosized Ni@C core-shell particles in wide temperature and frequency ranges.

\section{Methodology}

$\mathrm{Ni}$ nanoparticles covered with carbon $\mathrm{Ni@C}$ were produced by evaporation of an overheated $\left(2000{ }^{\circ} \mathrm{C}\right.$ ) liquid drop of $\mathrm{Ni}$ in the flow of inert gas (Ar) containing a hydrocarbon (butane). Two types of acid treatments (with $\mathrm{HCl}$ or $\mathrm{HF}$ ) were used to remove metal oxide from the nanocomposites. As a result, a carbon encapsulated core-shell structure was produced. Carbon layers are ordered and arranged well and closely compacted to form the quasi onion nanostructure and surround the nickel nanoparticles. The size of Ni nanoparticles ranges from 2 to $10 \mathrm{~nm}$. The nanocapsules contain a metal particle encapsulated in the cavity, and the outer shell is composed of several carbon layers of a few nanometers in thickness [30-32].

The polydimethylsiloxane (PDMS), Sylgard, was purchased from Dow-Corning (Midland, MI, USA) as a two-part material. Ni@C nanoparticles were dispersed in isopropanol (IPA) and sonicated to break up the agglomerates. After obtaining the homogeneous dispersion, the uncured PDMS was added to the mixture. Next, the system was placed into a vacuum to remove isopropanol from the mixture. Curing of the PDMS-nanoparticle mixture at $60^{\circ} \mathrm{C}$ for $2 \mathrm{~h}$ and $40{ }^{\circ} \mathrm{C}$ overnight resulted in films with good nanoparticle dispersion (see Figure 1) [33]. Samples with 1, 5, 7, 9, and 11 vol \% of $\mathrm{Ni@C} \mathrm{dispersed} \mathrm{in} \mathrm{PDMS} \mathrm{were} \mathrm{prepared.}$

The complex dielectric permittivity was measured using the HP4284A LCR meter in the frequency range $20 \mathrm{~Hz}-1 \mathrm{MHz}$. For temperature measurements (130-430 K), the homemade heater and the cooling system based on liquid nitrogen were used. Samples with a typical $4 \mathrm{~mm}^{2}$ cross section and a $0.5 \mathrm{~mm}$ thickness were studied. The silver paint was used for contacts. Magnetic properties were studied with a Liquid Helium Free High Field Measurement System (Cryogenic Ltd., London, UK). The system includes a closed-cycle cryostat. Samples of a typical mass of $500 \mathrm{mg}$ were studied at a temperature range of $20-300 \mathrm{~K}$, and field properties were measured with magnetic fields of $-5-5 \mathrm{~T}$. 


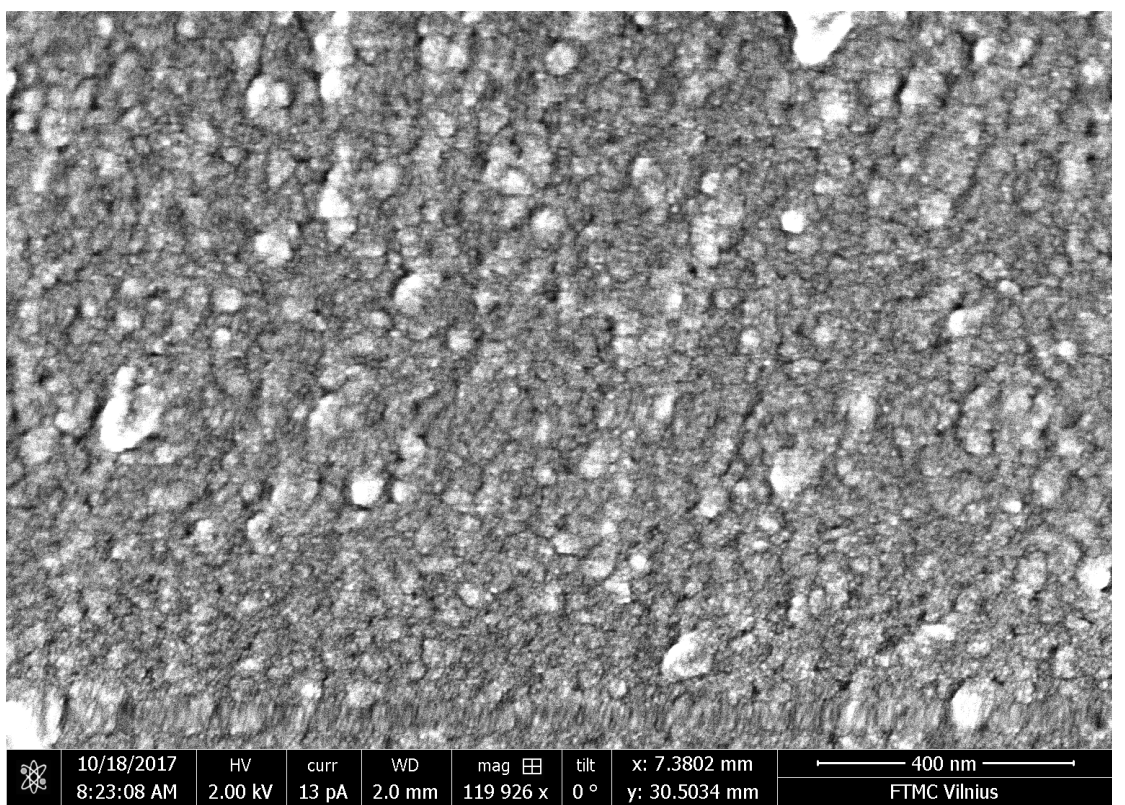

Figure 1. Scanning electron microscopy of composite material with 3 vol \% of Ni@C.

\section{Experimental Results}

\subsection{Dielectric Properties}

The frequency dependencies of real and imaginary parts of dielectric permittivity of Ni@C/PDMS composite materials at room temperature are presented in Figure 2a.
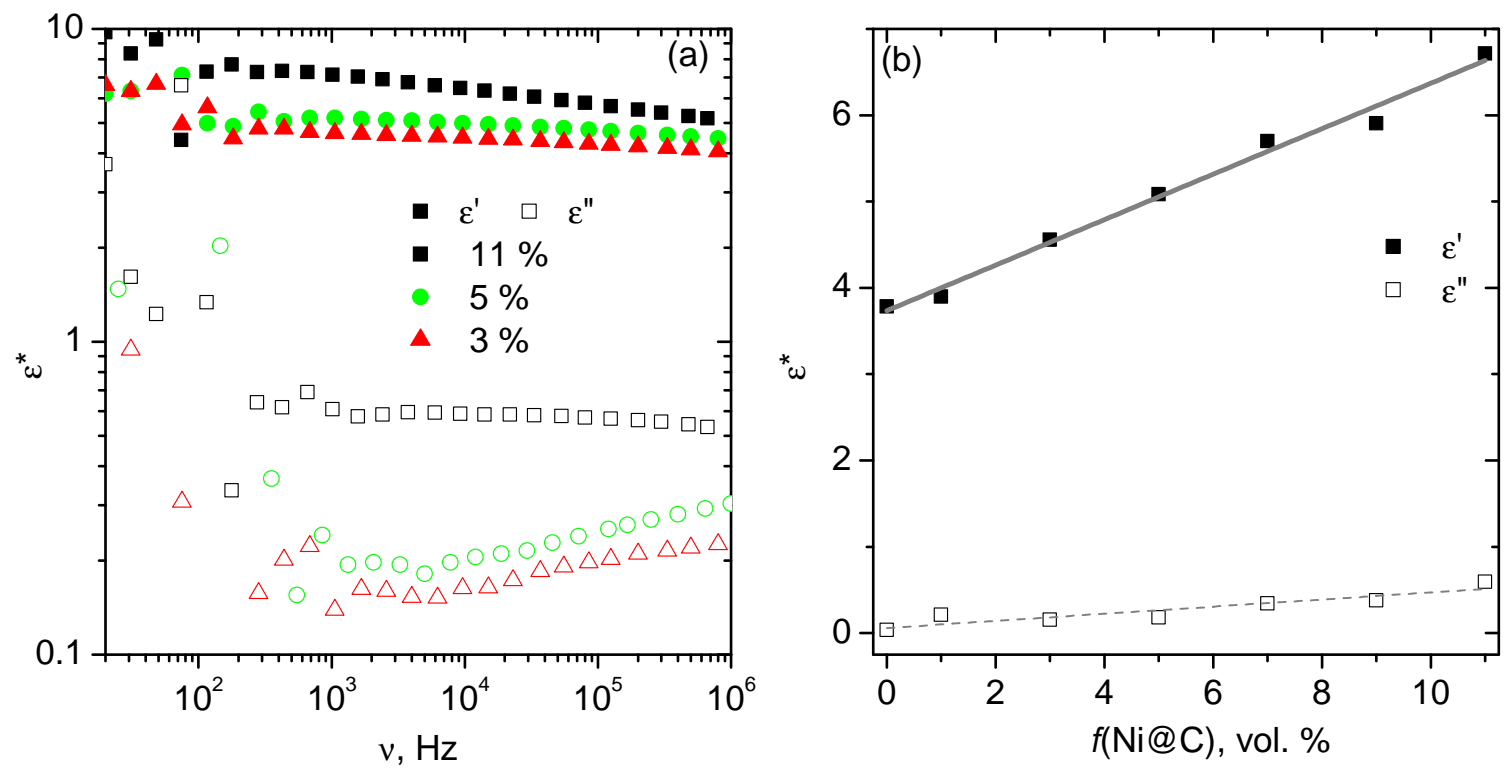

Figure 2. (a) Frequency dependence of the permittivity of Ni@C/PDMS composite with different amounts of embedded Ni@C particles, (b) dependence of the permittivity on Ni@C fraction at $4 \mathrm{kHz}$ frequency(symbols), fit with Maxwell Garnett equation (lines).

Loading the samples with $\mathrm{Ni@C} \mathrm{particles} \mathrm{leads} \mathrm{to} \mathrm{the} \mathrm{increase} \mathrm{of} \mathrm{both} \mathrm{real} \mathrm{and} \mathrm{imaginary} \mathrm{parts} \mathrm{of}$ permittivity. The concentration dependence of permittivity at a fixed frequency (it was taken as $4 \mathrm{kHz}$, 
see Figure 2b, symbols) is almost linear. This type of behavior is governed by the Maxwell Garnett equation [34]:

$$
\varepsilon^{*}=\varepsilon_{h}^{*} \frac{1+2 / 3 \alpha f}{1-1 / 3 \alpha f}
$$

where $\varepsilon_{h}^{*}$ is the complex permittivity of the matrix host, $\alpha$ is the polarizability of inclusions, and $f$ is the volume fraction of inclusions. The theoretical prediction of the percolation concentration for spherical particles using the shape functionals method predicts its value as $28.54 \mathrm{vol} \%$ [35], and the Monte Carlo method predicts value as $31.2 \mathrm{vol} \%$ [36], so studied concentration values can be considered as small, and Equation (1) may be simplified to linear [37]: $\varepsilon \sim f$ (Figure 2b), lines).

Temperature dependences of the dielectric permittivity of composite materials at a fixed frequency of $24 \mathrm{kHz}$ are presented in Figure 3.
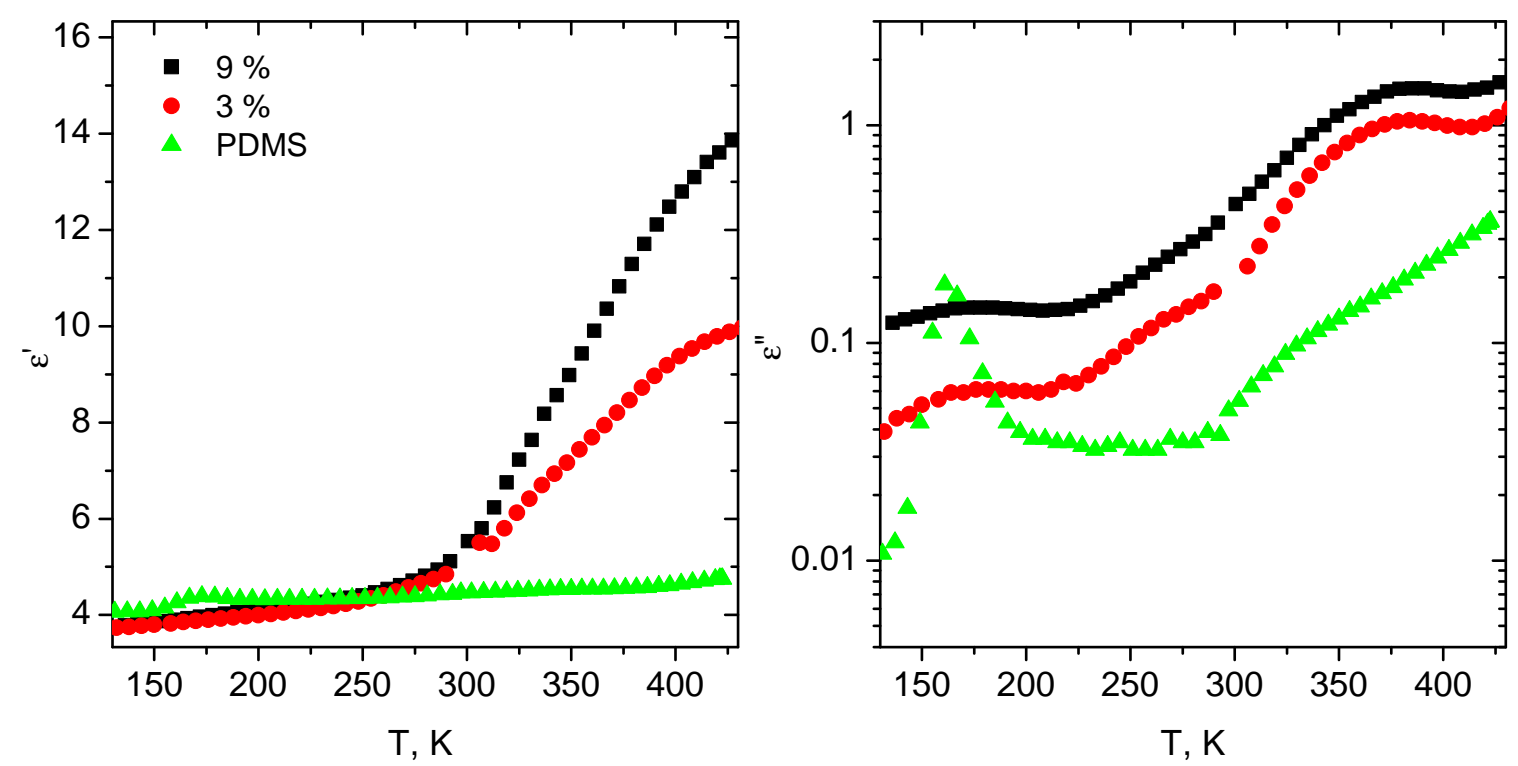

Figure 3. Temperature dependences of the dielectric permittivity of the composite materials at $24 \mathrm{kHz}$ with different amount of Ni@C.

The anomalous behavior of the permittivity of the pure PDMS matrix was observed close to $160 \mathrm{~K}$. This behavior is related to the dynamic glass transition of PDMS [38]. The presence of Ni@C nanoparticles significantly changes the temperature behavior of the permittivity. Firstly, the peak at low temperatures becomes broader, and the temperature correspondent to the maximum of the dielectric loss shifts. A second peak of the imaginary part of the dielectric permittivity appears near $375 \mathrm{~K}$. The position of both peaks of dielectric losses was found to be frequency-dependent (see Figure 4a).

Let us consider the anomalies of the imaginary part of the permittivity occurring at low temperatures. It can be seen that, with the frequency increase, the maximum shifts to higher temperatures and becomes smaller. The temperatures of dielectric losses maximum at different frequencies for all studied samples was tracked and collected and are shown in Figure 4b.

This dependence follows the Vogel-Fulcher law [39]:

$$
v=v_{0} \exp \frac{-E_{V F}}{k_{b}\left(T_{\max }-T_{r e f}\right)}
$$

where $T_{r e f}$ is the static glass transition temperature or the Vogel temperature, $T_{\max }$ is the temperature corresponding to the maximum of the dielectric losses (known as the dynamic glass transition temperature), $k_{b}$ is the Boltzmann constant, and $E_{V F}$ is the activation energy. As shown in Equation (2), 
there is a divergence of $v$ when $T_{\max }$ approaches $T_{r e f}$, and this indicates that the thermally activated process slows down with decreasing temperature and vanishes at $\mathrm{T}=T_{\text {ref }}$, but not at $\mathrm{T}=0 \mathrm{~K}$ as prescribed by the Arrhenius law. Therefore, $T_{r e f}$ can be considered critical for describing the transition in such a system [40]. The parameters of best fits of experimental data are shown in Table 1. As we can see, the glass transition temperature increases with the concentration of nanofiller.
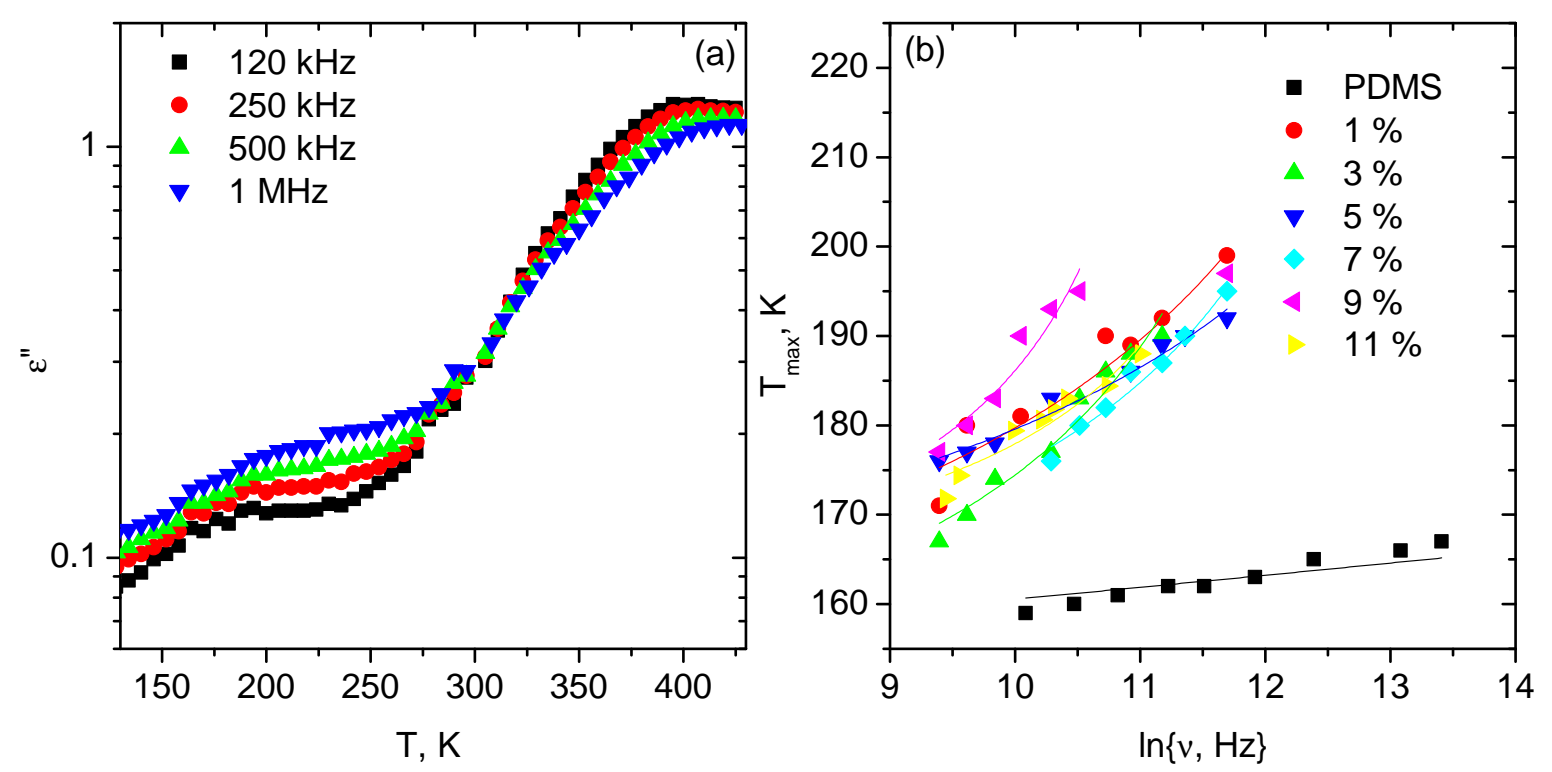

Figure 4. Typical temperature dependence of dielectric losses at different frequencies-here, 5 vol \% $\mathrm{Ni@C/PDMS} \mathrm{(a).} \mathrm{Measured} \mathrm{frequencies} \mathrm{versus} T_{\max }$ for composites with different concentrations of $\mathrm{Ni@C}$ at lower temperatures $(\mathbf{b})$.

Table 1. Glass transition temperature, Vogel-Fulcher, and activation energies of Ni@C/PDMS composites.

\begin{tabular}{ccccc}
\hline Ni@C vol \% & $T_{\boldsymbol{r e f}}, \mathbf{K}$ & $E_{V F} / \boldsymbol{k}_{\boldsymbol{b}}, \mathbf{K}$ & $\boldsymbol{v}_{\mathbf{0}}, \mathbf{k H z}$ & $E_{\boldsymbol{a}} / \boldsymbol{k}_{\boldsymbol{b}}, \mathbf{K}$ \\
\hline 11 & 154.9 & 71.1 & 484.4 & 20,206 \\
9 & 152.3 & 69.7 & 172.1 & 18,423 \\
7 & 142.8 & 144.6 & 1870.01 & 16,926 \\
5 & 142.4 & 238.2 & $13,224.7$ & 18,199 \\
3 & 136.3 & 139.5 & 857.8 & 17,960 \\
1 & 130.1 & 298.0 & 8763.9 & - \\
\hline
\end{tabular}

Frequency spectra of real and imaginary parts of dielectric permittivity at different temperatures were also studied. It was found that the sample with $11 \mathrm{vol} \%$ demonstrates relaxation behavior. In particular, a maximum of dielectric losses was observed in dielectric spectra. However, the strength of the relaxation is quite small (see Figure 5a, symbols). Frequency spectra of $\varepsilon^{\prime \prime}$ may be described with the Cole-Cole equation (Figure 5a, solid line curves):

$$
\varepsilon^{*}(v)=\varepsilon_{\infty}+\frac{\Delta \varepsilon}{1+(i 2 \pi \nu \tau)^{1-\alpha}} .
$$

The relaxation strength $\Delta \varepsilon$ and the parameter $\alpha$ demonstrate the weak dependence on temperature, while the relaxation time has a more complicated temperature dependency. As obtained, the relaxation time was recalculated to the relaxation frequency as $1 / \tau$. The temperature dependence of the relaxation frequency is presented in Figure 5. Two different regions can be clearly seen. The first region is above $150 \mathrm{~K}$, where the relaxation time increases with cooling. The relaxation frequency demonstrates the Arrhenius behavior. In the second temperature region, below $150 \mathrm{~K}$, the relaxation time becomes 
temperature-independent. We may conclude that these two regions correspond to amorphous and crystalline phases. This is in good agreement with data shown in Table 1.
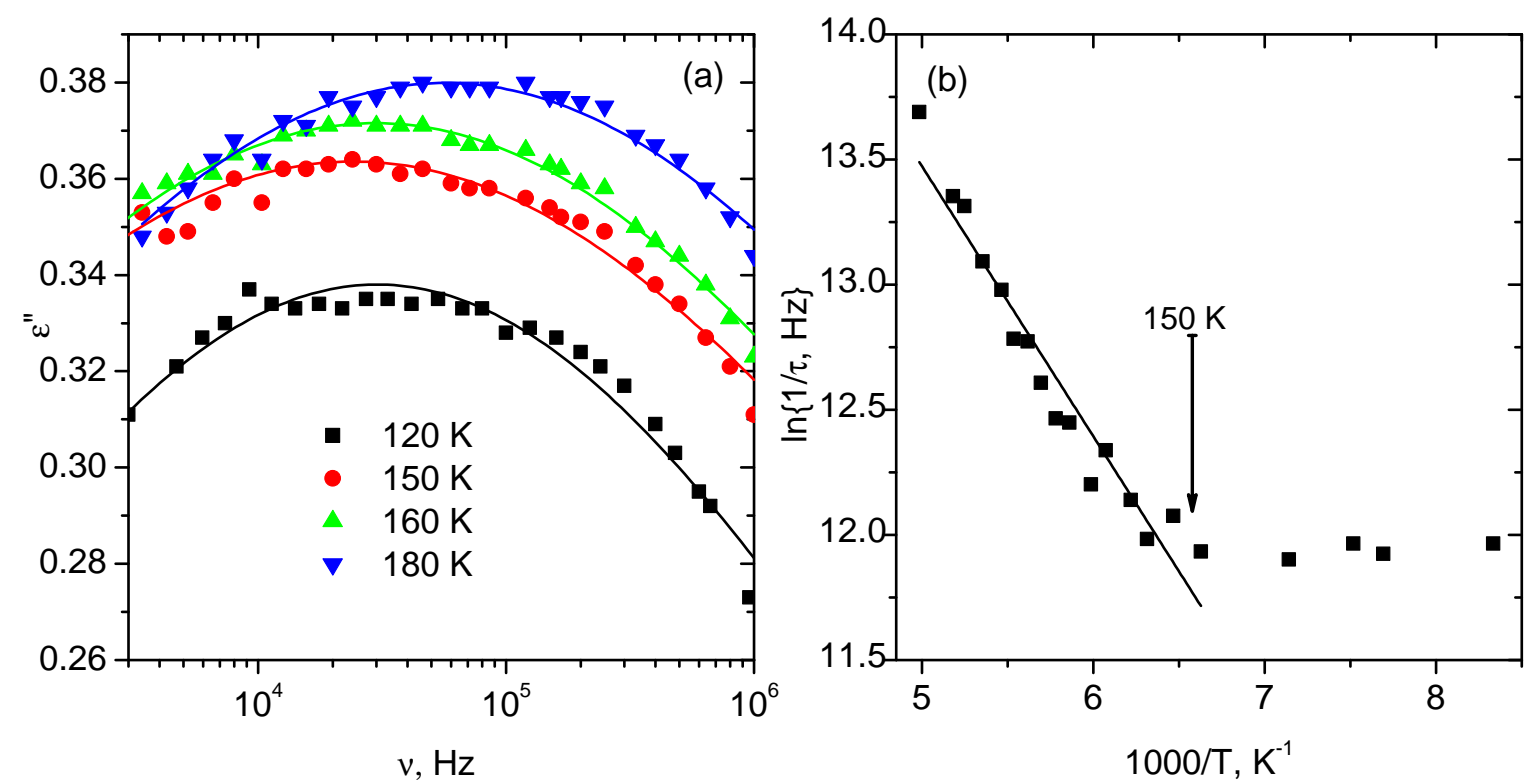

Figure 5. Frequency spectra of composite with 11 vol \% of Ni@C (a). Temperature dependence of relaxation time for composites with 11 vol \% of $\mathrm{Ni@C} \mathrm{(b).}$

Composites with the lower concentration of Ni@C should also demonstrate the relaxation peak in $\varepsilon^{\prime \prime}(v)$ spectra, but the dielectric dispersion in composites is much broader and weaker, so it is practically impossible to identify the peak in the dielectric spectra of composites.

The glass transition in polymers is strongly related to the mobility of polymer molecules [41]. As temperature decreases, mobility reduces. However, the addition of nanoparticles with high specific surface area may also impact the mobility. There are several possibilities. In a case where polymer chains interact with particles, mobility is reduced, and the glass temperature increases [42,43]. On the other hand, if the interaction of nanoparticles and polymer chains is weak, the density of the polymer decrease, and, as a result, $T_{g}$ decreases $[44,45]$. We can assume that, being introduced into the PDMS matrix, Ni@C interact with polymer.The glass transition occurs at higher temperatures. In this case, $\mathrm{Ni@C} 108$ can play the role of crystallization nuclei, similarly to other nanoparticles [46].

As mentioned above, the second anomalous behavior of dielectric losses is observed at higher temperatures (Figure 4). In contrast to the glass transition maxima, this peak was not observed for the pure PDMS matrix. Thus, we may assume that this maximum is related to interfacial Maxwell-Wagner relaxation.

At higher temperatures, the maximum of dielectric losses was also found to be frequency-dependent. Applying the same protocol described above, we have accurately tracked the frequency dependence of temperature where the maximum of dielectric losses occurs. The dependence of the maximum position may be well described by Arrhenius law. Activation energies $E_{a}$ are shown in Table 1. Except for samples with $7 \mathrm{vol} \% \mathrm{Ni@C}$, activation energies increase with concentration.

We can conclude that the addition of the Ni@C nanoparticles strongly influences the properties of the composites. Firstly, by means of Ni@C concentration, we can monotonously change the $T_{g}$ of the composites. This may happen because the nanoparticles are bonded with polymer chains. At higher temperatures, the Maxwell-Wagner relaxation may occur due to the polarization on the interface of conductive particles and the non-conductive polymer matrix. 


\subsection{Magnetic Properties}

The field M(B) dependencies for the samples with different concentrations of Ni@C inclusions at $300 \mathrm{~K}$ are presented in Figure 6 (symbols). The curves are slightly shifted from the zero point and demonstrate negligibly small remanent magnetizations of 0.009 and $0.015 \mathrm{emu} / \mathrm{g}$ and coercive forces of 0.0094 and $0.00916 \mathrm{~T}$ for 7 and $11 \mathrm{vol} \%$, correspondingly. The composite with $7 \mathrm{vol} \% \mathrm{Ni@C}$ achieve the saturation of magnetization at external fields of $0.813 \mathrm{~T}$, while the sample with $11 \mathrm{vol} \%$ does not demonstrate any saturation even at very high fields. The weak diamagnetic effect of the $7 \mathrm{vol} \% \mathrm{Ni} @ \mathrm{C}$ composite at high fields (see Figure 6, inset) is related to the diamagnetic properties of the polymer [47]. The dependence of magnetization is governed by Langevin's law (Figure 6 (solid lines)):

$$
M=M_{s}\left(\operatorname{coth}\left(\frac{\mu H}{k_{B} T}\right)-\frac{k_{B} T}{\mu H}\right) .
$$
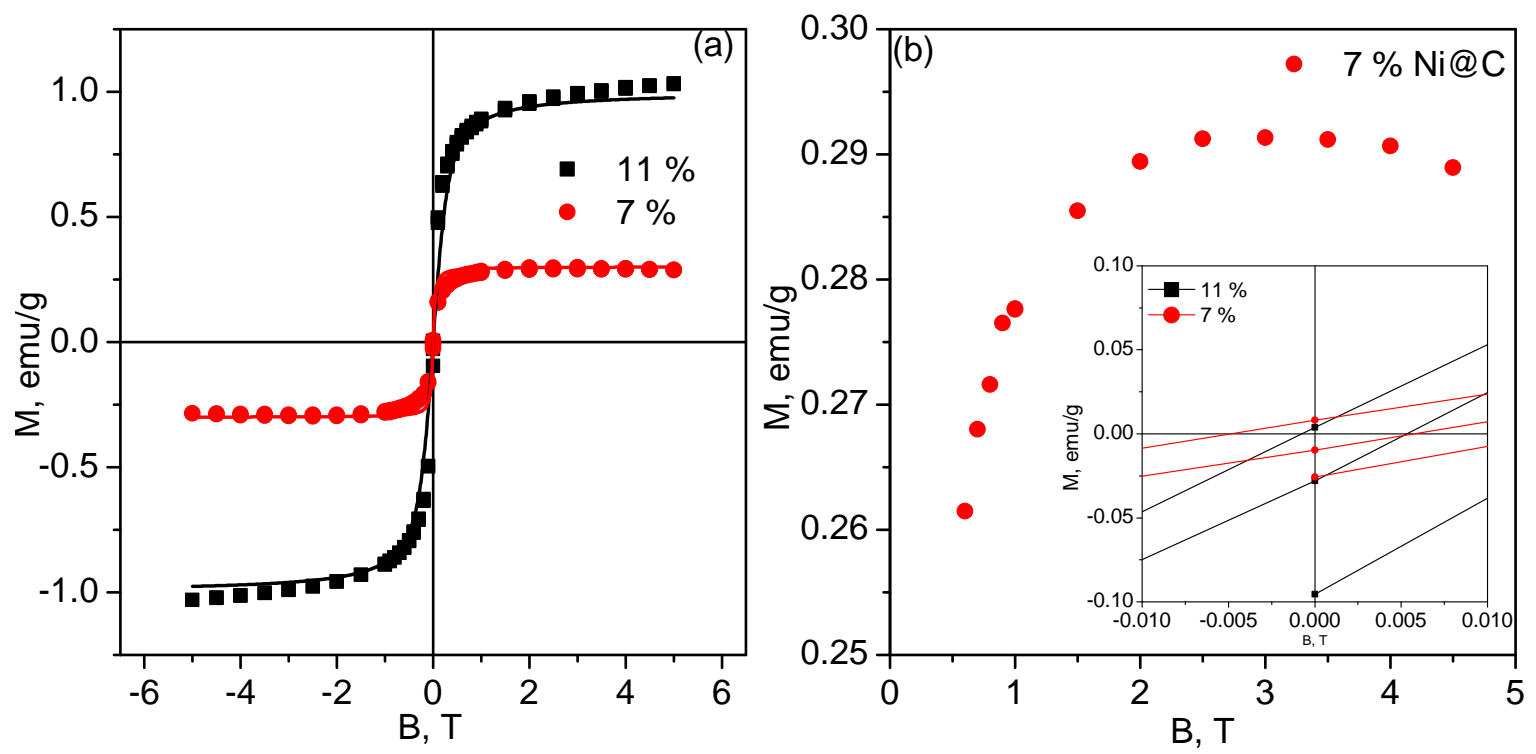

Figure 6. Field dependence of the magnetization of samples with different concentrations of $\mathrm{Ni@C} \mathrm{at} 300 \mathrm{~K}$ (a). Diamagnetic effect of the sample with 7 vol \% of Ni@C at high magnetic fields (b). Inset: the field dependence around zero-point

The field dependence is typical for composites with superparamagnetic particles [48-50].

The temperature dependences of magnetization were measured in two modes: (i) the sample was cooled under an external magnetic field with a small value of $17 \mathrm{mT}$, the field cooling (FC), and (ii) the sample was previously cooled without an external field, a field of $17 \mathrm{mT}$ was then switched on, and the magnetization of sample was measured upon heating, the zero field curve (ZFC). The results of measurements are presented as relative magnetizations as $\mathrm{M}(\mathrm{T}) /\left.\mathrm{M}(20 \mathrm{~K})\right|_{Z F C}$ in Figure 7 . The absolute values of $\left.\mathrm{M}(20 \mathrm{~K})\right|_{Z F C}$ are 1.75, 0.016, and $0.0017 \mathrm{emu} / \mathrm{g}$ for pure Ni@C powder and the composites with 11 and $7 \mathrm{vol} \%$ of $\mathrm{Ni} @ \mathrm{C}$, respectively. The wide maximum of magnetization of both composite samples as well as the pure Ni@C powder was observed in ZFC mode. The temperatures of the magnetization maxima are close to $120 \mathrm{~K}$ for all samples. Such behavior is an argument for the superparamagnetic nature of the particles. The temperature of the magnetization maximum is known as the blocking temperature $\left(T_{B}\right)$ [51]. Being single domain, the particle has the magnetization vector in the external field along the easy axis of magnetization, and the random switching of the magnetization vector directions is the thermally activated process. At particular temperatures $\left(T_{B}\right)$, "freezing" occurs. The obtained value of $T_{B}$ is higher, which was reported for similar particles of smaller size [51]. The difference may be related to a strong $T_{B}$ dependence on particle size [52] and its 
distribution. The broadness of the maximum that is evident from the distribution of Ni@C particle sizes causes the distribution of energy barrier [53,54]. FC curves demonstrate the increase in magnetization upon cooling. It is known that $\mathrm{Ni}$ particles with a $5 \mathrm{~nm}$ diameter demonstrate a phase transition to ferromagnetic phases in the studied temperature range [48]. Liu et al. [49] reported a value of $100 \mathrm{~K}$. Near the phase transition temperature, the FC M(T) dependencies demonstrate slope changing [49]. We observed a similar behavior in studied samples at a temperature of $70 \mathrm{~K}$; however, in contrast to [49], we evaluated our measurements at low field, significantly lower than the saturation field, so in our case, this change in slope is substantially diffused.
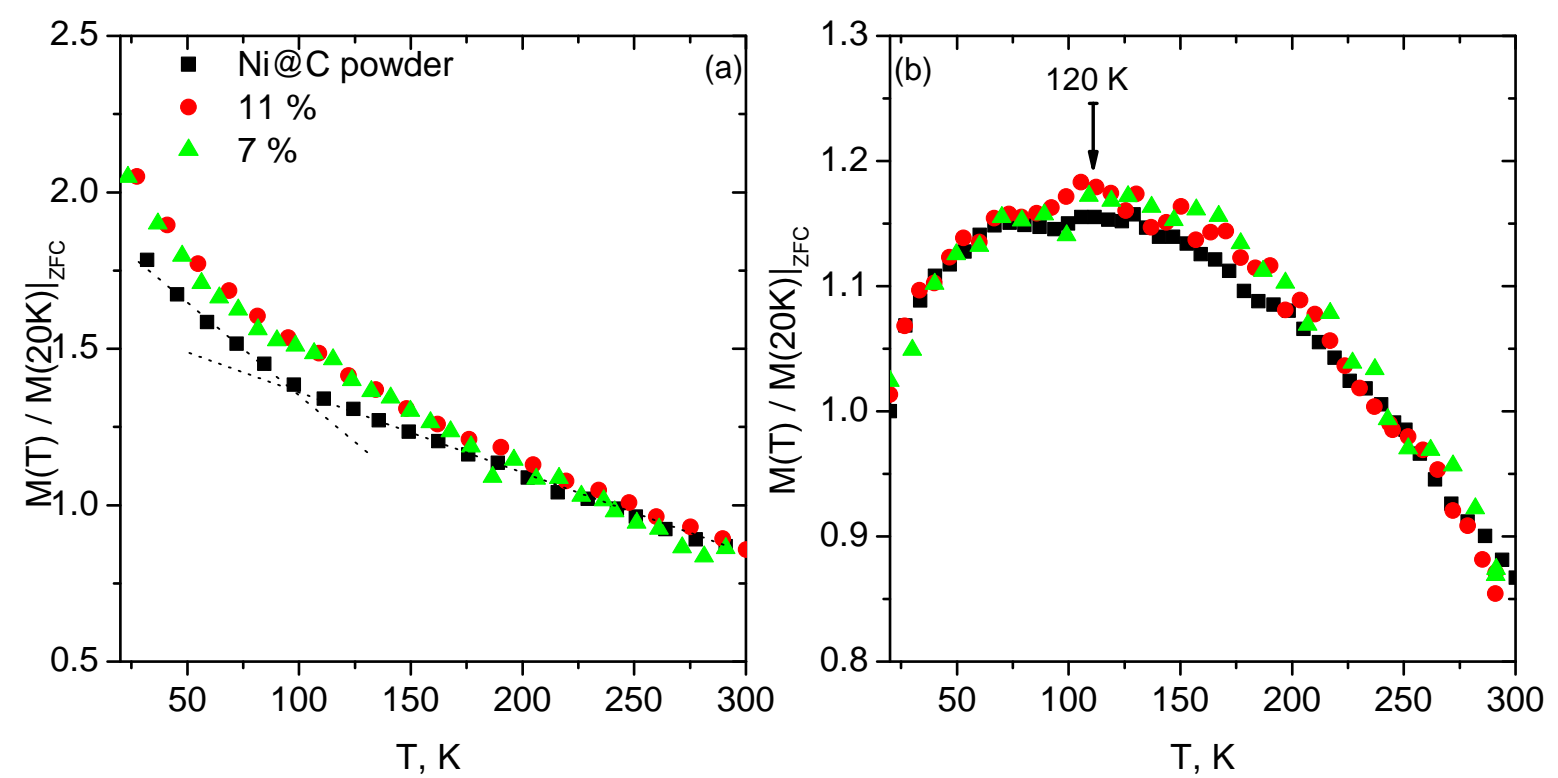

Figure 7. FC (a) and ZFC (b) dependencies of the relative magnetization as $M(T) /\left.M(T=20 K)\right|_{Z F C}$ for $\mathrm{Ni@C} \mathrm{powder} \mathrm{and} \mathrm{for} \mathrm{composite} \mathrm{samples} \mathrm{with} \mathrm{different} \mathrm{concentrations} \mathrm{of} \mathrm{Ni@C} \mathrm{measured} \mathrm{at} 117 \mathrm{mT}$.

We can conclude that $\mathrm{Ni@C} \mathrm{particles} \mathrm{demonstrate} \mathrm{superparamagnetic} \mathrm{properties} \mathrm{at} \mathrm{room}$ temperature, which is confirmed by the behavior of the ZFC and FC curves.

\section{Discussion and Conclusions}

Dielectric properties of composites with core-shell Ni@C nanoparticles embedded in a poly(dimethylsiloxane) matrix were studied in wide frequency $(20 \mathrm{~Hz}-1 \mathrm{MHz})$ and temperature $(130-430 \mathrm{~K})$ ranges. The permittivity linearly increased from $3.74-0.034 i$ up to $6.71-0.59 i$ for the pure PDMS and the sample with $11 \mathrm{vol} \% \mathrm{Ni@C}$ at $4 \mathrm{kHz}$ at room temperature. However, the temperature behavior of the dielectric properties of the composites changed significantly as the $\mathrm{Ni@C}$ fraction changed. An anomaly of the dielectric properties of both the PDMS and the composite samples, related to the glass transition of the PDMS, was observed near $160 \mathrm{~K}$. Glass transition temperature increased monotonously with $\mathrm{Ni@C} \mathrm{concentrations} \mathrm{from} 130$ to $154 \mathrm{~K}$. The dielectric anomaly for composites with Ni@C close to $375 \mathrm{~K}$ is related to Maxwell-Wagner relaxation. Dielectric properties were governed by $\alpha$-relaxation of the polymer at lower temperatures and the Maxwell-Wagner relaxation in the high-temperature region. These magnetic investigations demonstrate the superparamagnetic nature of Ni@C particles. The blocking temperature was $120 \mathrm{~K}$ for all studied samples. Due to the magnetic properties at certain applied magnetic fields (see Figure 6), impedance matching may be easier when organizing them into regular structures of particular geometries [27-29] by, e.g., 3D printing, which allows for the development of a wide range of passive electromagnetic components, such as frequency-selective filters, wide-band detectorssensors of a bolometric type, and even electromagnetic perfect absorbers (so-called "black holes" or wave concentrators). 
Author Contributions: Olga Shenderova prepared the composites, Artyom Plyushch and Jan Macutkevič performed dielectric measurements and analyzed the corresponding results, Nikolay Kalanda and Alexander Petrov did magnetic measurements, Mikhail A. Uimin and Anatoly Ye. Yermakov provide magnetic nanoparticles, Clara Silvestre and Jūras Banys took part in data analysis, Artyom Plyushch, Jan Macutkevič and Polina Kuzhir conceived and designed the experiments and wrote the manuscript.

Acknowledgments: The authors acknowledge with thanks the financial supports from the Multifunctional Graphene-Based Nanocomposites with Robust Electromagnetic and Thermal Properties for 3D-Printing Application, project H2020 RISE 734164 Graphene 3D. The data analysis of the temperature dependence of relaxation time for composites filled with Ni@C was carried out at Tomsk Polytechnic University within the framework of Tomsk Polytechnic University Competitiveness Enhancement Program grant. Mikhail A. Uimin and Anatoly Ye. Yermakov are thankful to project "Magnet" No. AAAA-A18-118020290129-5.

Conflicts of Interest: The authors declare no conflict of interest.

\section{References}

1. Ausanio, G.; Hison, C.L.; Iannotti, V.; Lanotte, L.; Lanotte, L. Magneto-piezoresistance in elastomagnetic composites. J. Appl. Phys. 2011, 110, 063903. [CrossRef]

2. Rocha-Santos, T.A. Sensors and biosensors based on magnetic nanoparticles. TrAC Trends Anal. Chem. 2014, 62, 28-36. [CrossRef]

3. Freitas, P.; Ferreira, R.; Cardoso, S.; Cardoso, F. Magnetoresistive sensors. J. Phys. Condens. Matter 2007, 19, 165221. [CrossRef]

4. Mocanu, Z.; Airimioaei, M.; Ciomaga, C.; Curecheriu, L.; Tudorache, F.; Tascu, S.; Iordan, A.; Palamaru, N.; Mitoseriu, L. Investigation of the functional properties of $\mathrm{Mg}_{x} \mathrm{Ni}_{1-x} \mathrm{Fe}_{2} \mathrm{O}_{4}$ ceramics. J. Mater. Sci. 2014, 49, 3276-3286. [CrossRef]

5. Dumitrescu, A.; Lisa, G.; Iordan, A.; Tudorache, F.; Petrila, I.; Borhan, A.; Palamaru, M.; Mihailescu, C.; Leontie, L.; Munteanu, C. Ni ferrite highly organized as humidity sensors. Mater. Chem. Phys. 2015, 156, 170-179. [CrossRef]

6. Mohr, R.; Kratz, K.; Weigel, T.; Lucka-Gabor, M.; Moneke, M.; Lendlein, A. Initiation of shape-memory effect by inductive heating of magnetic nanoparticles in thermoplastic polymers. Proc. Nat. Acad. Sci. USA 2006, 103, 3540-3545. [CrossRef] [PubMed]

7. Schmidt, A.M. Electromagnetic activation of shape memory polymer networks containing magnetic nanoparticles. Macromol. Rapid Commun. 2006, 27, 1168-1172. [CrossRef]

8. Pankhurst, Q.A.; Connolly, J.; Jones, S.; Dobson, J. Applications of magnetic nanoparticles in biomedicine. J. Phys. D Appl. Phys. 2003, 36, R167. [CrossRef]

9. Berry, C.C.; Curtis, A.S. Functionalisation of magnetic nanoparticles for applications in biomedicine. J. Phys. D Appl. Phys. 2003, 36, R198. [CrossRef]

10. Liu, X.; Li, B.; Geng, D.; Cui, W.; Yang, F.; Xie, Z.; Kang, D.; Zhang, Z. (Fe, Ni)/C nanocapsules for electromagnetic-wave-absorber in the whole Ku-band. Carbon 2009, 47, 470-474. [CrossRef]

11. Wu, N.; Liu, X.; Zhao, C.; Cui, C.; Xia, A. Effects of particle size on the magnetic and microwave absorption properties of carbon-coated nickel nanocapsules. J. Alloys Compd. 2016, 656, 628-634. [CrossRef]

12. Li, Y.; Wang, J.; Liu, R.; Zhao, X.; Wang, X.; Zhang, X.; Qin, G. Dependence of gigahertz microwave absorption on the mass fraction of Co@C nanocapsules in composite. J. Alloys Compd. 2017, 724, 1023-1029. [CrossRef]

13. Xie, Z.; Geng, D.; Liu, X.; Ma, S.; Zhang, Z. Magnetic and microwave-absorption properties of graphite-coated (Fe, Ni) nanocapsules. J. Mater. Sci. Technol. 2011, 27, 607-614. [CrossRef]

14. Liu, X.; Ou, Z.; Geng, D.; Han, Z.; Jiang, J.; Liu, W.; Zhang, Z. Influence of a graphite shell on the thermal and electromagnetic characteristics of FeNi nanoparticles. Carbon 2010, 48, 891-897. [CrossRef]

15. Fujii, T. PDMS-based microfluidic devices for biomedical applications. Microelectron. Eng. 2002, 61, 907-914. [CrossRef]

16. Comina, G.; Suska, A.; Filippini, D. PDMS lab-on-a-chip fabrication using 3D printed templates. Lab Chip 2014, 14, 424-430. [CrossRef] [PubMed]

17. Clarson, S.; Dodgson, K.; Semlyen, J. Studies of cyclic and linear poly (dimethylsiloxanes): 19. Glass transition temperatures and crystallization behavior. Polymer 1985, 26, 930-934. [CrossRef] 
18. Choi, K.M.; Rogers, J.A. A photocurable poly (dimethylsiloxane) chemistry designed for soft lithographic molding and printing in the nanometer regime. J. Am. Chem. Soc. 2003, 125, 4060-4061. [CrossRef] [PubMed]

19. Xia, Y.; Whitesides, G.M. Soft lithography. Ann. Rev. Mater. Sci. 1998, 28, 153-184. [CrossRef]

20. Whitesides, G.M.; Ostuni, E.; Takayama, S.; Jiang, X.; Ingber, D.E. Soft lithography in biology and biochemistry. Ann. Rev. Biomed. Eng. 2001, 3, 335-373. [CrossRef] [PubMed]

21. Zhang, J.; Yang, B. Patterning colloidal crystals and nanostructure arrays by soft lithography. Adv. Funct. Mater. 2010, 20, 3411-3424. [CrossRef]

22. Jin, X.; Deng, M.; Kaps, S.; Zhu, X.; Hölken, I.; Mess, K.; Adelung, R.; Mishra, Y.K. Study of tetrapodal ZnO-PDMS composites: A comparison of fillers shapes in stiffness and hydrophobicity improvements. PLoS ONE 2014, 9, e106991. [CrossRef] [PubMed]

23. Canavese, G.; Lombardi, M.; Stassi, S.; Pirri, C.F. Comprehensive characterization of large piezoresistive variation of Ni-PDMS composites. In Applied Mechanics and Materials; Trans Tech Publications: Zurich, Switzerland, 2012; Volume 110, pp. 1336-1344.

24. Chu, K.; Kim, D.; Sohn, Y.; Lee, S.; Moon, C.; Park, S. Electrical and thermal properties of carbon-nanotube composite for flexible electric heating-unit applications. IEEE Electron Device Lett. 2013, 34, 668-670. [CrossRef]

25. Chen, D.; Chen, F.; Hu, X.; Zhang, H.; Yin, X.; Zhou, Y. Thermal stability, mechanical and optical properties of novel addition cured PDMS composites with nano-silica sol and MQ silicone resin. Compos. Sci. Technol. 2015, 117, 307-314. [CrossRef]

26. Varga, Z.; Filipcsei, G.; Zrínyi, M. Magnetic field sensitive functional elastomers with tuneable elastic modulus. Polymer 2006, 47, 227-233. [CrossRef]

27. Letellier, M.; Macutkevic, J.; Bychanok, D.; Kuzhir, P.; Delgado-Sanchez, C.; Naguib, H.; Mosanenzadeh, S.G.; Fierro, V.; Celzard, A. Modelling the physical properties of glasslike carbon foams. In Journal of Physics: Conference Series; IOP Publishing: Bristow, UK, 2017; Volume 879, p. 012014.

28. Letellier, M.; Macutkevic, J.; Kuzhir, P.; Banys, J.; Fierro, V.; Celzard, A. Electromagnetic properties of model vitreous carbon foams. Carbon 2017, 122, 217-227. [CrossRef]

29. Kuzhir, P.P.; Letellier, M.; Bychanok, D.S.; Paddubskaya, O.; Suslyaev, V.I.; Korovin, E.Y.; Baturkin, S.; Fierro, V.; Celzard, A. Electrical properties of carbon foam in the microwave range. Rus. Phys. J. 2017, 59, 1703-1709. [CrossRef]

30. Galakhov, V.; Shkvarin, A.; Semenova, A.; Uimin, M.; Mysik, A.; Shchegoleva, N.; Yermakov, A.Y.; Kurmaev, E. Characterization of carbon-encapsulated nickel and iron nanoparticles by means of X-ray absorption and photoelectron spectroscopy. J. Phys. Chem. C 2010, 114, 22413-22416. [CrossRef]

31. Erokhin, A.; Lokteva, E.; Yermakov, A.Y.; Boukhvalov, D.; Maslakov, K.; Golubina, E.; Uimin, M. Phenylacetylene hydrogenation on Fe@C and Ni@C core-shell nanoparticles: about intrinsic activity of graphene-like carbon layer in $\mathrm{H}_{2}$ activation. Carbon 2014, 74, 291-301. [CrossRef]

32. Tsurin, V.; Yermakov, A.Y.; Uimin, M.; Mysik, A.; Shchegoleva, N.; Gaviko, V.; Maikov, V. Synthesis, structure, and magnetic properties of iron and nickel nanoparticles encapsulated into carbon. Phys. Solid State 2014, 56, 287-301. [CrossRef]

33. Macutkevic, J.; Kranauskaite, I.; Banys, J.; Moseenkov, S.; Kuznetsov, V.; Shenderova, O. Metal-insulator transition and size dependent electrical percolation in onion-like carbon/polydimethylsiloxane composites. J. Appl. Phys. 2014, 115, 213702. [CrossRef]

34. Garnett, J.C.M. Colours in Metal Glasses and in Metallic Films. Phils. Trans. R. Soc. Lond. A 1904, 203, 385-420. [CrossRef]

35. Garboczi, E.J.; Snyder, K.A.; Douglas, J.F.; Thorpe, M.F. Geometrical percolation threshold of overlapping ellipsoids. Phys. Rev. E 1995, 52, 819-828. [CrossRef]

36. Kirkpatrick, S. Percolation phenomena in higher dimensions: Approach to the mean-field limit. Phys. Rev. Lett. 1976, 36, 69. [CrossRef]

37. Bychanok, D.; Kanygin, M.; Okotrub, A.V.; Shuba, M.; Paddubskaya, A.; Pliushch, A.; Kuzhir, P.; Maksimenko, S. Anisotropy of the electromagnetic properties of polymer composites based on multiwall carbon nanotubes in the gigahertz frequency range. JETP Lett. 2011, 93, 607-611. [CrossRef]

38. Fragiadakis, D.; Pissis, P.; Bokobza, L. Glass transition and molecular dynamics in poly (dimethylsiloxane)/ silica nanocomposites. Polymer 2005, 46, 6001-6008. [CrossRef] 
39. Vogel, H. The law of the relation between the viscosity of liquids and the temperature. Physical Z 1921, 22, 645-646.

40. Bai, Y.; Jin, L. Characterization of frequency-dependent glass transition temperature by Vogel-Fulcher relationship. J. Phys. D Appl. Phys. 2008, 41, 152008. [CrossRef]

41. Sun, Y.; Zhang, Z.; Moon, K.S.; Wong, C. Glass transition and relaxation behavior of epoxy nanocomposites. J. Polym. Sci. Part B Polym. Phys. 2004, 42, 3849-3858. [CrossRef]

42. Becker, C.; Krug, H.; Schmidt, H. Tailoring of thermomechanical properties of thermoplastic nanocomposites by surface modification of nanoscale silica particles. MRS Online Proc. Libr. Arch. 1996, 435. [CrossRef]

43. Chen, K.; Yang, S. Synthesis of epoxy-montmorillonite nanocomposite. J. Appl. Polym. Sci. 2002, 86, 414-421. [CrossRef]

44. Ash, B.; Schadler, L.; Siegel, R. Glass transition behavior of alumina/polymethylmethacrylate nanocomposites. Mater. Lett. 2002, 55, 83-87. [CrossRef]

45. Arrighi, V.; McEwen, I.; Qian, H.; Prieto, M.S. The glass transition and interfacial layer in styrene-butadiene rubber containing silica nanofiller. Polymer 2003, 44, 6259-6266. [CrossRef]

46. Belovickis, J.; Macutkevic, J.; Svirskas, Š.; Samulionis, V.; Banys, J.; Shenderova, O.; Borjanovic, V. Ultrasonic and dielectric relaxations in PDMS/ZnO nanocomposite. Phys. Status Solidi B 2015, 252, 2778-2783. [CrossRef]

47. Gass, J.; Poddar, P.; Almand, J.; Srinath, S.; Srikanth, H. Superparamagnetic polymer nanocomposites with uniform $\mathrm{Fe}_{3} \mathrm{O}_{4}$ nanoparticle dispersions. Adv. Funct. Mater. 2006, 16, 71-75. [CrossRef]

48. Kumar, A.; Tandon, R.; Awana, V. Successive spin glass, cluster ferromagnetic, and superparamagnetic transitions in $\mathrm{RuSr}_{2} \mathrm{Y}_{1.5} \mathrm{Ce}_{0.5} \mathrm{Cu}_{2} \mathrm{O}_{10}$ complex magneto-superconductor. Eur. Phys. J. B 2012, 85, 238. [CrossRef]

49. Liu, X.; Huang, K.; Zhou, S.; Zhao, P.; Meridor, U.; Frydman, A.; Gedanken, A. Phase transition from the ferromagnetic to superparamagnetic with a loop shift in 5-nm nickel particles. J. Magn. Magn. Mater. 2006, 305, 504-508. [CrossRef]

50. Virlan, C.; Tudorache, F.; Pui, A. Tertiary NiCuZn ferrites for improved humidity sensors: A systematic study. Arabian J. Chem. 2018. [CrossRef]

51. Hou, Y.; Gao, S. Monodisperse nickel nanoparticles prepared from a monosurfactant system and their magnetic properties. J. Mater. Chem. 2003, 13, 1510-1512. [CrossRef]

52. Ngo, A.; Bonville, P.; Pileni, M. Spin canting and size effects in nanoparticles of nonstoichiometric cobalt ferrite. J. Appl. Phys. 2001, 89, 3370-3376. [CrossRef]

53. Mishra, A.; Bandyopadhyay, S.; Das, D. Structural and magnetic properties of pristine and Fe-doped NiO nanoparticles synthesized by the co-precipitation method. Mater. Res. Bull. 2012, 47, 2288-2293. [CrossRef]

54. Sardar, D.; Sengupta, M.; Bordoloi, A.; Ahmed, M.A.; Neogi, S.; Bandyopadhyay, S.; Jain, R.; Gopinath, C.S.; Bala, T. Multiple functionalities of Ni nanoparticles embedded in carboxymethyl guar gum polymer: catalytic activity and superparamagnetism. Appl. Surf. Sci. 2017, 405, 231-239. [CrossRef]

(c) 2018 by the authors. Licensee MDPI, Basel, Switzerland. This article is an open access article distributed under the terms and conditions of the Creative Commons Attribution (CC BY) license (http://creativecommons.org/licenses/by/4.0/). 